\title{
УДК 547
}

\section{НОВЫЕ ФЕРРОЦЕНСОДЕРЖАЩИЕ ПРОИЗВОДНЫЕ ТИОФЕНА}

\author{
Е. Н. Родловская*, В. А. Васнев \\ Представлено академиком РАН А.Р. Хохловым 19.04.2019 г.
}

Поступило 29.04.2019 г.

\begin{abstract}
По реакции Гевальда синтезирован новый 2-амино-4-ферроценил-тиофен-3-карбонитрил, и на его основе получены основания Шиффа, прекурсоры для новых оптоэлектронных и магнитных материалов. Структура синтезированных соединений установлена методами элементного анализа, ИК- и ${ }^{1} \mathrm{H}$ ЯМР-спектроскопии.
\end{abstract}

Ключевые слова: реакция Гевальда, ацетилферроценилиденмалононитрил, аминотиофенкарбонитрил, основания Шиффа.

DOI: https://doi.org/10.31857/S0869-56524876626-629

Металлоорганические фрагменты, такие как ферроцен (бис- $\eta^{5}$-циклопентадиенилжелезо (II), $\left.\left(\eta^{5}-\mathrm{C}_{5} \mathrm{H}_{5}\right)_{2} \mathrm{Fe}, \mathrm{Cp}_{2} \mathrm{Fe}\right)$, включённые в $\pi$-конъюгированные системы, подобные тиофену (Th), представляют огромный интерес для исследователей в качестве фундаментальных основ синтеза металлоорганических полимеров, в том числе с целью получения моделей для изучения процессов переноса электронов [1, 2]. Известно, что ферроценилсодержащие соединения при соответствующей обработке образуют магнитные наночастицы [3, 4], а политиофен обладает дырочной проводимостью [5], что успешно применяется для создания оптоэлектронных и нитных материалов для различных устройств хранения информации, магнитных сенсоров и магнитных эластомеров [6, 7].

Цель работы - разработка фундаментальных основ синтеза нового тиофен- и ферроценсодержащего прекурсора (2-амино-4-ферроценил-тиофен-3-карбонитрил) для получения упорядоченных органогибридных ансамблей и создания новых материалов, обладающих уникальными механическими, электрическими, оптоэлектронными и парамагнитными свойствами.

Изучение полученных нами низкомолекулярных и полимерных соединений в качестве прекурсоров парамагнитных частиц крайне актуально, так как известно, что магнитными свойствами обладают оксиды железа (II, III) - магнетит $\mathrm{Fe}_{3} \mathrm{O}_{4}$ и родственные ему соединения (ферриты). Синтезированные нами соединения при окислительном тер-

Институт элементоорганических соединений им. А.Н. Несмеянова

Российской Академии наук, Москва

*E-mail: rodlovskaya@mail.ru мическом нагревании должны изомеризоваться, возможно, с частичным разложением в железосодержащие наночастицы сложного состава, например содержащие $\mathrm{Fe}, \mathrm{Fe}_{3} \mathrm{C}, \mathrm{Fe}_{2} \mathrm{O}_{3}, \mathrm{Fe}_{3} \mathrm{O}_{4}, \mathrm{FeS}$ и др. Парамагнетизм предполагается в связи с тем, что монохалькогениды 3d-переходных металлов обладают большим разнообразием проявляющихся в них типов магнитного упорядочения, некоторые из них являются полупроводниками [8, 9]. Моносульфид железа при высоких температурах обладает никельарсенидной структурой. В сульфиде железа состава, близкого к стехиометрическому, переход из антиферромагнитного состояния в парамагнитное наблюдается при температуре $600 \mathrm{~K}$ [10].

2-амино-4-ферроценил-тиофен-3-карбонитрил II был получен по реакции Гевальда [11], которая заключается во взаимодействии карбонильных соединений с достаточно реакционноспособной карбонильной группой, имеющей в $\alpha$-положении метиленовую группировку, с соответствующими нитрилами и серой в присутствии оснований. Следует отметить, что металлоценовые производные никогда ранее не использовались в реакции Гевальда.

При взаимодействии ацетилферроцена с малононитрилом в присутствии основания, проводимом в бензоле с отгонкой воды с насадкой Дина-Старка, образуется ацетилферроценилиденмалононитрил I с выходом 92\%. Далее при взаимодействии I с элементарной серой и также в присутствии основания илиденпроизводное гладко циклизуется в 2-аминотиофен II с выходом 68\% (схема 1).

Чтобы лучше понять характер процессов, происходящих при синтезе ферроценсодержаших тиофенов, был проведён анализ ${ }^{1} \mathrm{H}$ ЯМР- и ИК-спектров ферроценсодержащих продуктов I и II. 


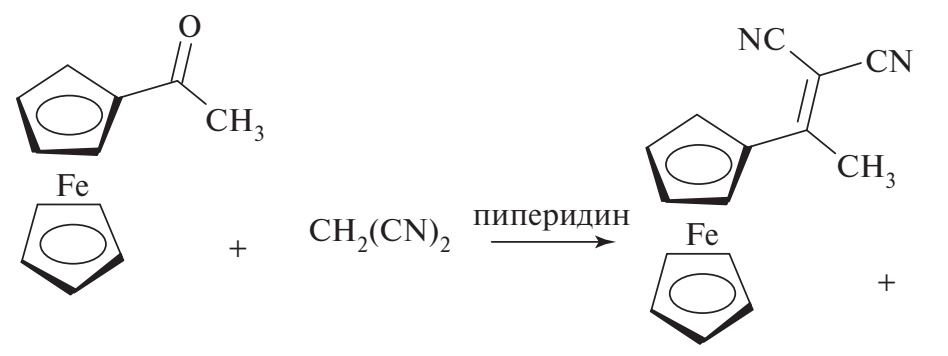

(I)

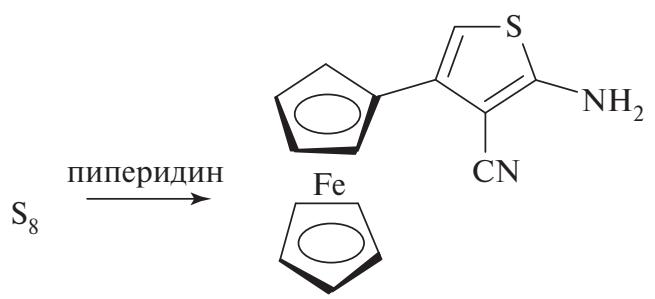

(II)

Схема 1

Известно, что первая часть, реакция Кнёвенагеля [11], протекает по механизму нуклеофильного присоединения: основание (катализатор) отщепляет протон от активной метиленовой группы малононитрила. Образовавшийся карбанион : $\mathrm{CH}(\mathrm{CH})_{2}$ реагирует с карбонильной группой ферроценового метилкетона, в результате чего выделяется вода. В качестве продуктов образуются $\alpha, \beta$-сопряжённые еноны, к сожалению, ${ }^{1} \mathrm{H}$ ЯМР-спектр в данном случае малоинформативен, так как повторяет ${ }^{1} \mathrm{H}$ ЯМР-спектр исходного ацетилферроцена. Наиболее информативным в данном случае является ИК-спектр соединения I: исчезновение полосы поглощения карбонильной группы в районе 1850$1650 \mathrm{~cm}^{-1}$, при этом появляется широкая полоса в районе $2255 \mathrm{~cm}^{-1}$, соответствующая группе $\mathrm{CN}$.

На втором этапе, в процессе реакции циклизации по типу реакции Гевальда, образовались твёрдые продукты цвета охры с $T_{\text {плI }}=145-147^{\circ} \mathrm{C}$ и $T_{\text {плII }}=$ $=133-131{ }^{\circ} \mathrm{C}$. На то, что циклизация прошла полностью, указывают ${ }^{1} \mathrm{H}$ ЯМР-спектры полученных ортоаминонитроилов, а именно наличие уширенного синглета в области 8,40-8,50 м.д., соответствующего протонам $\mathrm{NH}_{2}$-группы. В ИК-спектре также наблюдается отличие продуктов реакции от илиденпроизводных: отсутствие колебаний в области $2255 \mathrm{~cm}^{-1} \mathrm{CN}$-группы и наличие новых полос поглощения в области $3320 \mathrm{~cm}^{-1}$, которые относятся к группе $\mathrm{NH}_{2}$.

С целью оценки возможности получения полишиффовых оснований - прекурсоров новых опто- электронных и магнитных материалов - были выполнены синтезы соответствующих азометинов (оснований Шиффа) с различными бензальдегидами по схеме 2, где:
a) $\mathrm{R}_{1}=\mathrm{Cl} ; \mathrm{R}_{2}=\mathrm{Cl} ; \mathrm{R}_{3}, \mathrm{R}_{4}, \mathrm{R}_{5}=\mathrm{H}$;
b) $\mathrm{R}_{1}=\mathrm{OH} ; \mathrm{R}_{2}, \mathrm{R}_{3}, \mathrm{R}_{4}=\mathrm{H} ; \mathrm{R}_{5}=\mathrm{Br}$;
c) $\mathrm{R}_{1}=\mathrm{OH} ; \mathrm{R}_{2}=\mathrm{OEt} ; \mathrm{R}_{2}, \mathrm{R}_{3}, \mathrm{R}_{4}=\mathrm{H}$;
d) $\mathrm{R}_{1}=\mathrm{OMe} ; \mathrm{R}_{2}=\mathrm{OMe} ; \mathrm{R}_{3}=\mathrm{OMe} ; \mathrm{R}_{4}, \mathrm{R}_{5}=\mathrm{H}$.

Все основания Шиффа получены кипячением в ТГФ аминотиофена II, при этом образуются жёлтокоричневые порошки с выходом 85-95\%, малорастворимые в спирте и ацетоне и растворимые в амидных растворителях. Очистку проводят твердофазной экстракцией в экстракторе Сокслета этанолом.

Строение полученных соединений II a-d было доказано данными элементного анализа, ИК- и ${ }^{1} \mathrm{H}$ ЯМР-спектроскопии (табл. 1).

По данным термогравиметрического анализа на воздухе температура 5\%-й потери массы соединений I, II, IIa-d составляет выше $350{ }^{\circ} \mathrm{C}$, полученные порошки разлагаются при температуре выше $600{ }^{\circ} \mathrm{C}$ с образованием чёрного коксового осадка $10-25 \%$, содержащего магнетит.

Таким образом, впервые синтезированы ацетилферроценилиденмалононитрил, 2-амино-4-ферроценил-тиофен-3-карбонитрил и серия оснований Шиффа на его основе. Данные соеднинения служат прототипом нового класса ферроценсодержащих тиофенкарбонитрилов - прекурсоров оптоэлектронных и магнитных материалов.<smiles>[R]c1c([R])c([R])c(C=O)c([R])c1[R]</smiles>

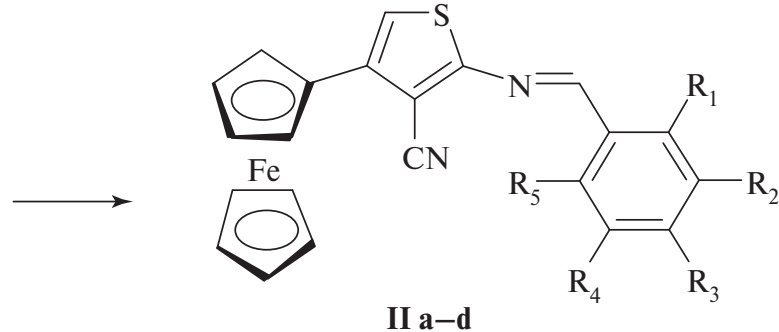

Схема 2 
Таблица 1. Результаты элементного анализа, ИК- и ${ }^{1} \mathrm{H}$ ЯМР-спектроскопии

\begin{tabular}{|c|c|c|c|c|c|c|c|c|c|c|}
\hline \multirow{2}{*}{$\begin{array}{l}\text { Соеди- } \\
\text { нение }\end{array}$} & \multirow[b]{2}{*}{$T_{\text {плл }},{ }^{\circ} \mathrm{C}$} & \multirow{2}{*}{$\begin{array}{c}\text { ИК-спектр, } \\
v, \mathrm{~cm}^{-1}\end{array}$} & \multirow{2}{*}{ ЯМР ${ }^{1} \mathrm{H}, \delta$, м.д. } & \multicolumn{6}{|c|}{ Элементный анализ, найдено/вычислено, \% } & \multirow{2}{*}{$\begin{array}{c}\text { Масс- } \\
\text { спектр, } \\
{\left[\mathrm{M}^{+}\right], m / z}\end{array}$} \\
\hline & & & & $\mathrm{C}$ & $\mathrm{H}$ & $\mathrm{N}$ & $\mathrm{Fe}$ & $\mathrm{S}$ & Галоген & \\
\hline IIa & $297-299$ & $\begin{array}{c}820(\mathrm{C}-\mathrm{H}), \\
1100(\mathrm{C}=\mathrm{C}), \\
1600(\mathrm{C}=\mathrm{NH}), \\
1450(\mathrm{C}=\mathrm{C}), \\
2250(\mathrm{CN})\end{array}$ & $\begin{array}{c}\text { 4,64 м., } 9 \mathrm{H}, \mathrm{Cp}_{2} \mathrm{Fe} \\
\text { 6,62 с., } 1 \mathrm{H}, \mathrm{Th} \\
\text { 6,89 с., } 1 \mathrm{H}, \mathrm{N}=\mathrm{CH} ; \\
\text { 7,62 м., } 3 \mathrm{H}, \mathrm{Ph}\end{array}$ & $\frac{56,35}{56,80}$ & $\frac{3,37}{3,03}$ & $\frac{5,86}{6,02}$ & $\frac{12,53}{12,01}$ & $\frac{7,01}{6,89}$ & $\begin{array}{c}\frac{14,92}{15,24} \\
(\mathrm{Cl})\end{array}$ & 464 \\
\hline IIIb & $285-287$ & $\begin{array}{c}830(\mathrm{C}-\mathrm{H}), \\
1150(\mathrm{C}=\mathrm{C}), \\
1610(\mathrm{C}=\mathrm{NH}), \\
1440(\mathrm{C}=\mathrm{C}), \\
2240(\mathrm{CN}), \\
3330(\mathrm{C}-\mathrm{O})\end{array}$ & $\begin{array}{c}\text { 4,66 м., } 9 \mathrm{H}, \mathrm{Cp}_{2} \mathrm{Fe} \\
\text { 6,60 с., } 1 \mathrm{H}, \mathrm{Th} \\
\text { 6,88 с., } 1 \mathrm{H}, \mathrm{N}=\mathrm{CH} ; \\
\text { 7,64 м., } 3 \mathrm{H}, \mathrm{Ph}\end{array}$ & $\frac{53,41}{53,80}$ & $\frac{3,55}{3,08}$ & $\frac{5,08}{5,70}$ & $\frac{11,81}{11,33}$ & $\frac{6,99}{6,53}$ & $\begin{array}{l}\frac{15,97}{16,27} \\
(\mathrm{Br})\end{array}$ & 491 \\
\hline IIc & $205-207$ & $\begin{array}{c}820(\mathrm{C}-\mathrm{H}), \\
1100(\mathrm{C}=\mathrm{C}), \\
1610(\mathrm{C}=\mathrm{NH}), \\
1450(\mathrm{C}=\mathrm{C}), \\
2240(\mathrm{CN}), \\
3320(\mathrm{C}-\mathrm{O})\end{array}$ & $\begin{array}{c}\text { 2,75 с., } 3 \mathrm{H}, \mathrm{CH}_{3} \\
3,92 \text { с., } 2 \mathrm{H}, \mathrm{OCH}_{2} \\
4,64 \text { м., } 9 \mathrm{H}, \mathrm{Cp}_{2} \mathrm{Fe} \\
\text { 6,61 с., } 1 \mathrm{H}, \mathrm{Th} \\
\text { 6,88 с., } 1 \mathrm{H}, \mathrm{N}=\mathrm{CH} ; \\
\text { 7,60 м., } 3 \mathrm{H}, \mathrm{Ph}\end{array}$ & $\frac{62,72}{63,17}$ & $\frac{4,87}{4,42}$ & $\frac{5,77}{6,14}$ & $\frac{12,71}{12,24}$ & $\frac{7,51}{7,03}$ & - & 456 \\
\hline IId & $261-263$ & $\begin{array}{c}820(\mathrm{C}-\mathrm{H}), \\
1100(\mathrm{C}=\mathrm{C}), \\
1610(\mathrm{C}=\mathrm{NH}), \\
1440(\mathrm{C}=\mathrm{C}), \\
250(\mathrm{CN}), \\
3410(\mathrm{C}-\mathrm{H})\end{array}$ & $\begin{array}{c}3,94 \text { с., } 9 \mathrm{H}, \mathrm{OCH}_{3} \\
\text { 4,63 м., } 9 \mathrm{H}, \mathrm{Cp}_{2} \mathrm{Fe} \\
\text { 6,62 с., } 1 \mathrm{H}, \mathrm{Th} \\
\text { 6,91 с., } 1 \mathrm{H}, \mathrm{N}=\mathrm{CH} ; \\
\text { 7,61 м., } 2 \mathrm{H}, \mathrm{Ph}\end{array}$ & $\frac{61,28}{61,74}$ & $\frac{5,01}{4,56}$ & $\frac{5,29}{5,76}$ & $\frac{11,98}{11,48}$ & $\frac{7,01}{6,59}$ & - & 486 \\
\hline
\end{tabular}

Примечание. ИК-спектры получены в таблетках KBr на приборе UR-2. Спектры ЯMP ${ }^{1} \mathrm{H}$ снимали на спектрометре Вruker Avance 400 (400 МГц) в ДМСО ${ }_{\mathrm{d} 6}$, внутренний стандарт $\mathrm{Me}_{4} \mathrm{Si}$. Масс-спектры получали на приборе KRATOS MS-890. Элементный анализ проводили на приборе Perkin-Elmer. $\mathrm{Cp}_{2} \mathrm{Fe}-$ ферроцен, Th - тиофен, $\mathrm{Ph}-$ фенилен.

Источники финансирования. Работа выполнена при финансовой поддержке Российского фонда фундаментальных исследований (грант № 18-03-00892). Регистрация спектров ЯМР, элементный анализ проведены при поддержке Министерства науки и высшего образования Российской Федерации с использованием научного оборудования Центра исследования строения молекул ИНЭОС РАН.

\section{СПИСОК ЛИТЕРАТУРЫ}

1. Jin B., Tao F., Liu P. Rapid-Scan Time-Resolved FT-IR Spectroelectrochemistry - Study on the Electron Transfer of Ferrocene-Substituted Thiophenes // J. Electroanalyt. Chem. 2008. V. 624. № 1/2. P. 179-185.

2. Tan L., Curtis M.D., Francis A.H. Charge Transfer in Ferrocene-Bearing Poly(thiophene)s and Application in Organic Bilayer Photocells // Macromolecules. 2002. V. 35. № 12. P. 4628-4635

3. Гуренцов Е.В. УФ-лазерный синтез наночастиц в газовой фазе // Кинетика и катализ. 2017. Т. 58. № 3. C. 241-265.

4. Saleem M., Yu H., Wang L., Abdin Z., Khalid H., Akram M., Abbasi N.M., Huang J. Review on Synthesis of Ferrocene-Based Redox Polymers and Derivatives and Their Application in Glucose Sensing // Anal. Chim. Acta. 2015. V. 876. P. 9-25.
5. Пономаренко А.Т., Тамеев А.Р., Шевченко В.Г. Синтез полимеров и модифицирование полимерных материалов в электромагнитных полях // Успехи химии. 2018. Т. 87. № 10. С. 923-949.

6. Muraoka H., Ogawa S. Synthesis and Electrochemical Properties of Ferrocene Dimers and Trimers Bridged by an Oligothiophene Space // Pure Appl. Chem. 2013. V. 85. № 4. P. 777-784.

7. Caballero A., T'arraga A., Velasco M.D., Molina P. Ferrocene-Thiophene Dyads with Azadiene Dpacers: Electrochemical, Electronic and Cation Sensing Properties // Dalton Trans. 2006. P. 1390-1398.

8. Кадкин О.Н., Галяметдинов Ю.Г. Ферроценсодержащие жидкие кристаллы // Успехи химии. 2012. T. 81. № 8. C. 675-699.

9. Дворикова Р.А., Васнёв В.А., Корлюков А.А., Бузин М.И. Магнитные и термические свойства наноматериалов на основе высокоразветвленных ферроценсодержащих полимеров // Тонкие химические технологии. 2018. Т. 13. № 5. С. 49-57.

10. Маковецкий Г.И., Янушкевич К.И. Структура и магнитные свойства твердых растворов системы сульфид железа - сульфид титана // Физика твердого тела. 1991. В. 11. С. 3280-3283.

11. Ли Дж. Именные реакции. Механизмы органических реакций / Пер. с англ. В.М. Демьянович. М.: Бином, Лаб. знаний, 2006. 456 с. 


\title{
NEW FERROCENSE CONTAINING TIOPHENE DERIVATIVES
}

\section{E. N. Rodlovskaya, V. A. Vasnev}

\author{
Nesmeyanov Institute of Organoelement Compounds of the Russian Academy of Sciences, \\ Moscow, Russian Federation
}

Presented by Academician of the RAS A.R. Khokhlov April 19, 2019

Received April 29, 2019

A new 2-amino-4-ferrocenyl-thiophene-3-carbonitrile was synthesized by the Gevald reaction and Schiff bases, precursors for new optoelectronic and magnetic materials, were obtained on its basis. The structures of the synthesized compounds were determined by elemental analysis, IR and ${ }^{1} \mathrm{H}$ NMR spectroscopy.

Keywords: Gewald reaction, acetylferrocenylidenemalononitrile, aminothiophenecarbonitrile, Schiff bases. 